\title{
Proliferative Retinopathy
}

National Cancer Institute

\section{Source}

National Cancer Institute. Proliferative Retinopathy. NCI Thesaurus. Code C155313.

Retinopathy characterized by the formation of new vessels in the retina. The new vessels are abnormal and fragile. If hemorrhage occurs due to the vascular fragility, there is increased risk of vision loss or blindness. 